\title{
Topical ophthalmic NSAIDs: a discussion with focus on nepafenac ophthalmic suspension
}

\author{
Bruce I Gaynes ${ }^{1,2}$ \\ Anne Onyekwuluje' \\ 'Departments of Ophthalmology \\ and ${ }^{2}$ Pharmacology, Rush College \\ of Medicine, Chicago, Illinois, USA
}

Correspondence: Bruce I Gaynes

Emailbgaynes@rush.edu

\begin{abstract}
The removal of diclofenac sodium ophthalmic solution as a viable pharmaceutical entity in September 1999 from the US market spurred considerable interest in the general safety and effectiveness of topical ophthalmic NSAIDs for treatment of anterior segment inflammation. In late 1999 the use of topical ocular NSAIDs declined in the US as a result of incidents involving corneal melts and toxicity surrounding use of generic diclofenac. However, since the removal of diclofenac sodium ophthalmic solution from the marketplace, ophthalmic NSAIDs have regained use as viable pharmacotherapeutic entities. Moreover, several new ophthalmic NSAID products have recently been introduced for commercial use in the US including the novel chemical entity nepafenac. The purpose of this report is to revisit the use of topical ophthalmic NSAIDs for the treatment of surgically induced anterior segment inflammation with a particular focus on nepafenac. Nepafenac is unique among ophthalmic NSAIDs in that it is a prodrug deaminated to amfenac, a highly effective non-selective cyclooxygenase inhibitor. In the case of topical ophthalmic NSAIDs, practitioners should carefully weigh the cost-benefit of implementing "highly potent" new drug products because perturbations in pharmacodynamic response due to the inherent novelty in terms of chemical designs may outweigh the demonstrated replicative pharmacologic action of all topical ophthalmic NSAIDs.
\end{abstract}

Keywords: ophthalmic NSAIDs, nepafenac, ocular inflammatory disease

\section{Introduction}

Prior to use of ophthalmic non-steroidal anti-inflammatory suspensions, topical ophthalmic steroids were the mainstay treatment of post-operative, surgically induced ocular inflammation. Although considered very effective, the use of topical corticosteroids is limited by well known side effects which in some serious cases can precipitate vision loss, and limits such therapy to short, intermittent use. Topical non-steroidal anti-inflammatory drugs (NSAIDs) are notable for a definitive lack of corticosteroiddefined toxicity and have secured an important role, albeit in some cases an undefined role, in the treatment of ocular inflammatory disease.

Acute inflammation can be the result of exogenous injury either iatrogenic or due to accidents as well as of endogenous origin such as occurs in autoimmune disease. The use of the term inflammation in the context of the present report, however, will be limited to that of inflammation due to exogenous origin secondary to post-operative ophthalmic surgery related to the production of various eicosanoids. Eicosanoids are defined as prostaglandins, leukotrienes, and other compounds that are products of the action of phospholipase A2 on the cellular phospholipid membrane and are, in general, derived from the production of arachidonic acid (Figure 1).

It has been shown that cyclooxygenase enzymes play a key role in maintaining cellular integrity and preventing apoptosis in eukaryotes (Xiaojun et al 1995). The eicosanoid products of cyclooxygenase play a vital role in cellular homeostasis such as modulation of platelet function as well as renal regulation of salt and water 


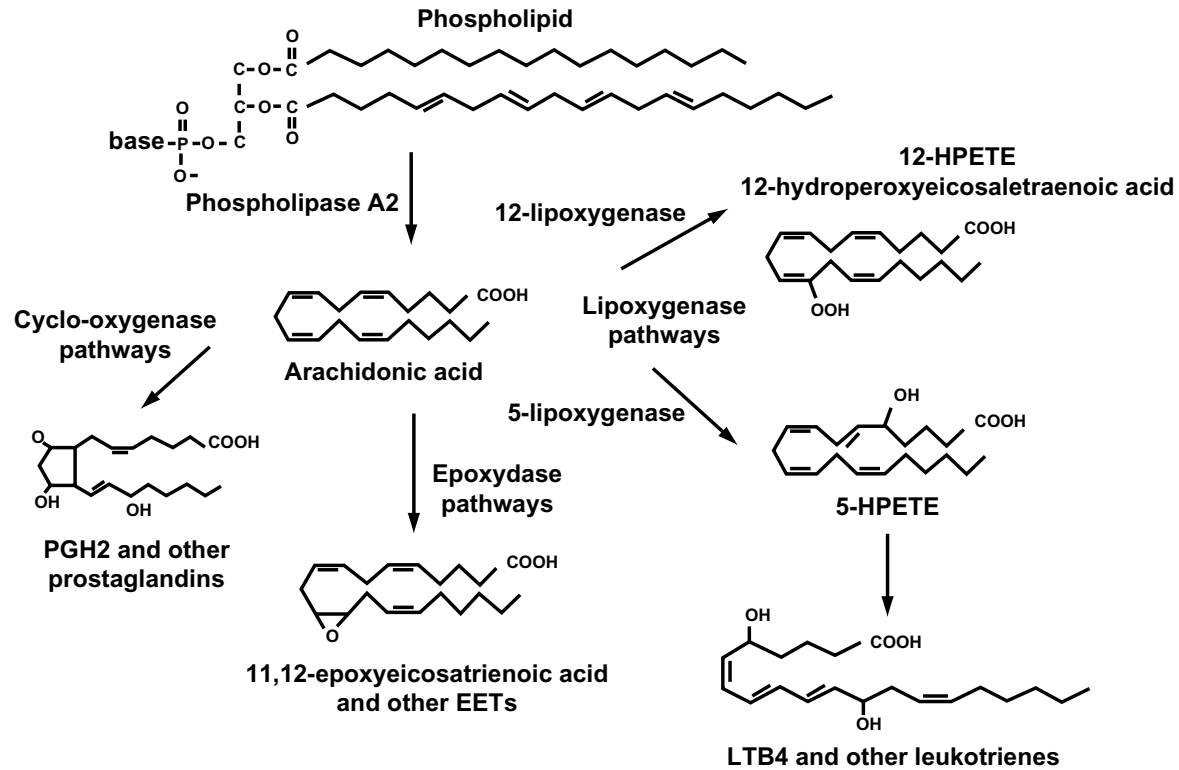

Figure I General pathways of arachidonic acid metabolism.

balance (Morrow and Roberts 2002). However, up-regulation of the cyclooxygenase enzyme system has been documented secondary to injury and results in overproduction of eicosanoids normally required for cellular homeostasis. An overabundance of eicosanoids converts these otherwise essential compounds to rampant mediators of inflammation. Unlike corticosteroids, which exhibit a broader effect on suppression of inflammation through inhibition of phospholipase A2 and through various cellular effects, NSAIDs act primarily through the inhibition of the cyclooxygenase (COX) enzyme isoforms. Interestingly, NSAIDs also have been demonstrated to exert anti-inflammatory activity by mechanisms unrelated to COX inhibition through suppression of polymorphonuclear (PMN) locomotion and chemotaxis as well as by decreasing expression of inflammatory cytokines and mast cell degranulation (Periann et al 1985; Leonardi et al 2000). There is also evidence that NSAIDs exert activity as free radical scavengers, a finding that may also contribute to lessen the inflammatory response (Flach 1992).

It is now well established that two forms of COX exist. A constitutive isoform, COX1, is equally expressed upon the endoplasmic reticulum of all cells including platelets, cellular elements of the small and large bowel mucosa, vascular endothelium renal medullary collecting ducts, interstitium, pulmonary and hepatic sites, as well as the spleen (Needleman and Isakson 1997). COX2 is the induced isoform formed in part by various cytokines and various inflammatory mediators secondary to inflammation (Crofford 1997). It is noteworthy that in the mammalian cornea, arachadonate may also be routed into a distinct metabolic pathway involving cytochrome P 450 (CYP) enzyme systems in addition to COX and lipoxygenase pathways (Figure 2) (Schwartzman and Abraham 1990). In the corneal epithelium, arachidonate is metabolized by CYP systems that results in the biologically active species, 12(R) - hydroxyl - 5,8,10,14 eicosatetraenoic acid [12(R) - HETE] and 12(R) - hydroxyl -5,8,14-eicosatetraenoic acid [12(R) - HETrE] (Schwartzman and Abraham 1990; Mieyal et al 2000). 12(R) - HETE is a potent inhibitor of $\mathrm{Na}^{+}-\mathrm{K}^{+}$ATPase as well as mediating PMN aggregation (Masferrer et al 1990; Mieyal et al 2000, 2001). 12(R) HETErE also plays a role in inflammation through mediation of conjunctival vasodilatation, and increasing permeability of the blood - aqueous barrier in addition to acting as an aggregate for PMN leukocytes (Davis et al 1990). Descriptive clinical ramifications of corneal inflammation derived from activity of the CYP systems remain to be further elucidated.

\section{Classification of NSAIDs}

Classification of NSAIDs is often noted by their chemical constituents as well as their activity on COX1 and COX2, respectively. NSAIDs available commercially for topical ophthalmic use are considered organic acids, with the exception of nepafenac, which is a benzoylbenzeneacetamide prodrug metabolized in vivo to its corresponding acid. Currently available ophthalmic NSAID products in the US are considered phenylacetic or phenylalkanoic acids, including nepafenac which is a substituted phenylacetic acid. Other chemical entities considered as NSAIDs such as salicylates, 


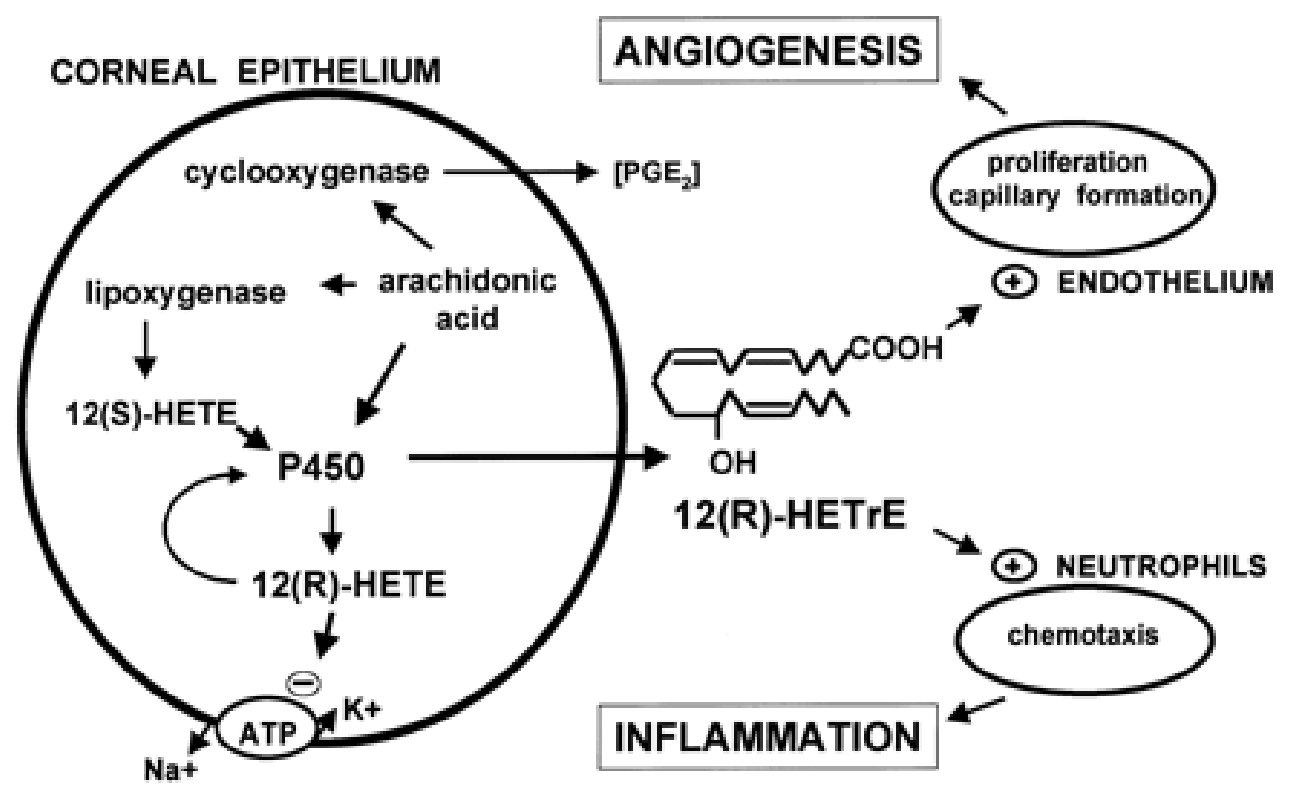

Figure 2 Pathways of arachadonate metabolism in the cornea. Reproduced with permission from Mieyal PA, Bonazzi A, jiang H, et al 2000. The effect of hypoxia on endogenous corneal epithelial eicosanoids. Invest OphthalmolVis Sci, 41:2170-6. Copyright $\odot$ 2000. Association for Research in Vision and Ophthalmology.

Abbreviations: CYP450, cytochrome P450; I2-HETE, I2(R)-hydroxy-5, 8, I I, I4-eicosatetraenoic acid; I2(R)-HETrE, I2(R)-hydroxy-5, 8, I4-eicosatrienoic acid; PG, prostaglandin.

fenamates and pyrazolone derivatives are considered too toxic for use in the eye (Flach 1992). An outline of currently used topical ophthalmic NSAIDs, their approved use in the US, as well as their chemical structure and class are outlined in Table 1 and Figure 3, respectively.

Commercially available topical ophthalmic NSAIDs are in large part solutions, with the exception of nepafenac which is a suspension, and vary based on the inclusion of inactive components utilized in embodiments as preservatives, surfactants, tonicity agents, viscosity enhancers, and buffers. As multi-use ophthalmic preparations require the presence of a preservative, the inclusion of anti-microbial compounds in the ophthalmic solution is imperative in the prevention of contamination of the solution.

As COX inhibition is the major outcome parameter of anti-inflammatory potential of NSAID application in vitro, the comparative effect of topical ophthalmic NSAIDs on COX1 and COX2 activities is also of interest, at least from an experimental standpoint. Classical NSAIDs with arylacetic acid structure are known to be potent inhibitors of the COX isoforms that promote a time-dependent inactivation of enzyme activity with increasing duration of drug exposure (Flach 1990). The inhibitory action against COX is markedly reduced, however, when arylacetic NSAIDs are esterified. Indeed, as an amide analog, nepafenac demonstrates weak COX activity; however its free acid, amfenac, is a potent inhibitor of both COX1 and COX2 isoforms (Gamache et al 2000). Topical NSAIDs differ based on their affinity for the
COX enzyme and activity in terms of enzyme inhibition. However, studies examining relative inhibitory COX activity of NSAIDs often utilize differing protocols and enzyme sources; therefore the comparative assessment of NSAID IC50 is not directly correlative.

It is important to exert caution when interpreting IC50 values for various NSAIDs in terms of clinical effectiveness. For example, COX activity can vary based solely on the species used to derive enzyme (Warner 2001). Furthermore, one must differentiate between in vitro testing at the cellular level or use of isolated enzymes. If one uses cells, a further caveat includes the inclusion of cofactors, for example glutathione or epinephrine that may affect enzyme rate (Warner 2001). Moreover, incubation times may vary, affecting rate of enzyme activity. Finally, the choice of an index of activity, eg, prostaglandin E2, thromboxane, or other markers of COX enzyme activity may affect determination of NSAID inhibitory potential (Warner 2001).

Despite the intuitive impulse to equate clinical effectiveness with NSAID potency, the non-parallel nature of inhibitor curves makes interpretation of IC50 levels clinically quite difficult (Warner 2001). It noteworthy to emphasize that potency does not equate to efficacy. Indeed potency is relatively unimportant in the overall scheme of pharmacotherapy as long as the chemical entity in and of itself is devoid of marked dose-dependent toxicity as is the generally the case with ophthalmic application of NSAIDs (Nies 2001; Lekhanont et al 2007). 
Table I Topical ophthalmic NSAID products approved for use in the US

\begin{tabular}{|c|c|c|}
\hline $\begin{array}{l}\text { Generic/marketed drug name (approved } \\
\text { for use in the US) }\end{array}$ & FDA-approved indications & Manufacturer recommended dosage \\
\hline \multirow[t]{2}{*}{$\begin{array}{l}\text { Diclofenac sodium ophthalmic solution } \\
0.1 \%\left(\text { Voltaren }^{\circledR}\right)\end{array}$} & $\begin{array}{l}\text { Post-operative inflammation after cataract } \\
\text { extraction }\end{array}$ & $\begin{array}{l}\text { Cataract surgery: I drop to the affected eye, } \\
4 \text { times daily beginning } 24 \text { hours after cataract } \\
\text { surgery and continuing throughout the first } \\
2 \text { weeks of the post-operative period. }\end{array}$ \\
\hline & $\begin{array}{l}\text { Post-operative pain and photophobia } \\
\text { following corneal refractive surgery }\end{array}$ & $\begin{array}{l}\text { Corneal refractive surgery: I or } 2 \text { drops should } \\
\text { be applied to the operative eye within the hour } \\
\text { prior to corneal refractive surgery. Within } \\
\text { I } 5 \text { min after surgery, I or } 2 \text { drops should be } \\
\text { applied to the operative eye and continued } \\
4 \text { times daily for up to } 3 \text { days. }\end{array}$ \\
\hline $\begin{array}{l}\text { Flurbiprofen ophthalmic solution } 0.03 \% \\
\text { (Ocufen }{ }^{\circledR}-\text { also available as a generic product } \\
\text { in the US) }\end{array}$ & $\begin{array}{l}\text { Inhibition of intra-operative miosis during } \\
\text { cataract surgery }\end{array}$ & $\begin{array}{l}\text { A total of } 4 \text { drops should be administered by } \\
\text { instilling I drop approximately every I/ } 2 \text { hour } \\
\text { beginning } 2 \text { hours before cataract surgery. }\end{array}$ \\
\hline \multirow{2}{*}{$\begin{array}{l}\text { Ketorolac tromethamine } 0.5 \% \text { ophthalmic } \\
\text { solution }\left(\operatorname{Acular}^{\circledR}\right)\end{array}$} & Seasonal allergic conjunctivitis & One drop 4 times a day as needed \\
\hline & $\begin{array}{l}\text { Post-op inflammation after cataract } \\
\text { extraction }\end{array}$ & $\begin{array}{l}\text { One drop } 4 \text { times a day beginning I day post- } \\
\text { operatively for } 14 \text { days }\end{array}$ \\
\hline $\begin{array}{l}\text { Ketorolac tromethamine } 0.4 \% \text { ophthalmic } \\
\text { solution (Acular LS }{ }^{\circledR} \text { ) }\end{array}$ & $\begin{array}{l}\text { Reduction of ocular pain and burning/stinging, } \\
\text { after corneal refractive surgery }\end{array}$ & $\begin{array}{l}\text { One drop } 4 \text { times a day in the operated eye as } \\
\text { needed for pain and burning/stinging for up to } \\
4 \text { days after corneal refractive surgery }\end{array}$ \\
\hline $\begin{array}{l}\text { Ketorolac tromethamine } 0.5 \% \text { ophthalmic } \\
\text { solution }\left(\mathrm{Acular} \mathrm{PF}^{\circledR}\right)\end{array}$ & $\begin{array}{l}\text { Reduction of ocular pain and photophobia } \\
\text { after incisional refractive surgery }\end{array}$ & $\begin{array}{l}\text { One drop } 4 \text { times a day in the operated eye } \\
\text { as needed for pain and photophobia for up to } \\
3 \text { days after incisional refractive surgery. }\end{array}$ \\
\hline $\begin{array}{l}\text { Bromfenac ophthalmic solution } 0.09 \% \\
\left(\text { Xibrom }^{T M}\right)\end{array}$ & $\begin{array}{l}\text { Post-op pain and Inflammation after cataract } \\
\text { extraction }\end{array}$ & $\begin{array}{l}\text { One drop twice daily beginning I day post- } \\
\text { operatively } \times 14 \text { days }\end{array}$ \\
\hline $\begin{array}{l}\text { Nepafenac ophthalmic suspension } 0.1 \% \\
\left(\text { Nevanac }^{\circledR}\right)\end{array}$ & $\begin{array}{l}\text { Post-operative pain and inflammation after } \\
\text { cataract extraction }\end{array}$ & $\begin{array}{l}\text { One drop } 3 \text { times daily beginning I day pre- } \\
\text { operatively, continued on day of surgery then } \\
\text { I } 4 \text { days post-operatively. }\end{array}$ \\
\hline
\end{tabular}

Although all topical ophthalmic NSAIDs may be considered non-selective COX inhibitors, the relative ratio of COX1:COX2 inhibitory potential of each agent differs markedly. In terms of COX isoforms demonstrable in corneal epithelium subsequent to experimentally induced hypoxiaderived inflammation, COX2 protein, but not COX1, was found to dramatically increase rabbit corneal epithelium after cellular hypoxia (Schwartzman et al 2003). COX2 protein has also been noted in the canine model of corneal inflammation as well (Schwartzman et al 2003; Sellars et al 2004). However, corneal inflammation as result of hypoxia was found unrelated to the presence of the inflammatory mediator PGE2 in the rabbit model. The lack of a concomitant increase in prostanoid PGE2 despite elevation in COX2 protein thereby suggests an alternative source of hypoxia-defined corneal inflammation aside from prostanoid compounds.

Of further interest, several studies have demonstrated that prostaglandins may in some cases have frank antiinflammatory properties and thus may be beneficial in combat- ing ocular inflammation. For example, PGE2 has been shown to inhibit LTB4-induced PMN infiltration into the anterior chamber of the rabbit eye (Kulkarni 1991). Furthermore, in the rabbit hypoxia model of corneal injury, inhibition of COX by indomethacin or aspirin resulted in potentiation of the release of PMNs into the tear film (Srinivasan and Kulkarni 1989). Although the role of prostaglandins in benefiting human corneal inflammation has not been tested, it is widely known that in general topical ophthalmic NSAIDs are only partially effective in reducing corneal inflammation in the human. NSAIDs may also potentiate peroximase proliferatoractivated receptors with subsequent induction of CYP4B1 activity and production of the pro-inflammatory compounds 12-HETE and 12-HETrE. If such is the case, topical NSAIDs may not only be ineffective in treating corneal inflammation in the human eye, but actually contribute to the inflammatory response. These findings back the general notion that topical NSAIDs are in general inferior to corticosteroids in treatment of ocular surface inflammation secondary to hypoxia (Srinivasan and Kulkarni 1989). 


\section{Nepafenac as an ophthalmic NSAID}

Since the introduction of topical indomethacin for use in ophthalmic disease, several generations of NSAID have been brought to market. One of the more recent products commercialized for topical ophthalmic use is nepafenac, a prodrug of amfenac approved for use in the US for the treatment of post-operative inflammation after cataract surgery. Nepafenac is described chemically as 2-amino-3-benzoylbenzeneacetamide manufactured as a $0.1 \%$ suspension for topical ophthalmic use (Gamache et al 2000).
Unlike other topical NSAIDs nepafenac is not a free acid and unique in that it is the first prodrug NSAID formulation. Until recently, all ophthalmic NSAID preparations, including flurbiprofen, diclofenac, ketorolac, and bromfenac, were relatively water-soluble phenylalkanoic and phenylacetic acids. Thus, due to their inherent water solubility, phenylalkanoic and phenylacetic acids would be predicted to have limited ability to penetrate corneal epithelium. Nepafenac, an amide prodrug analog of amfenac, is less polar and therefore ionic influences associated with corneal epithelial absorption are reduced.
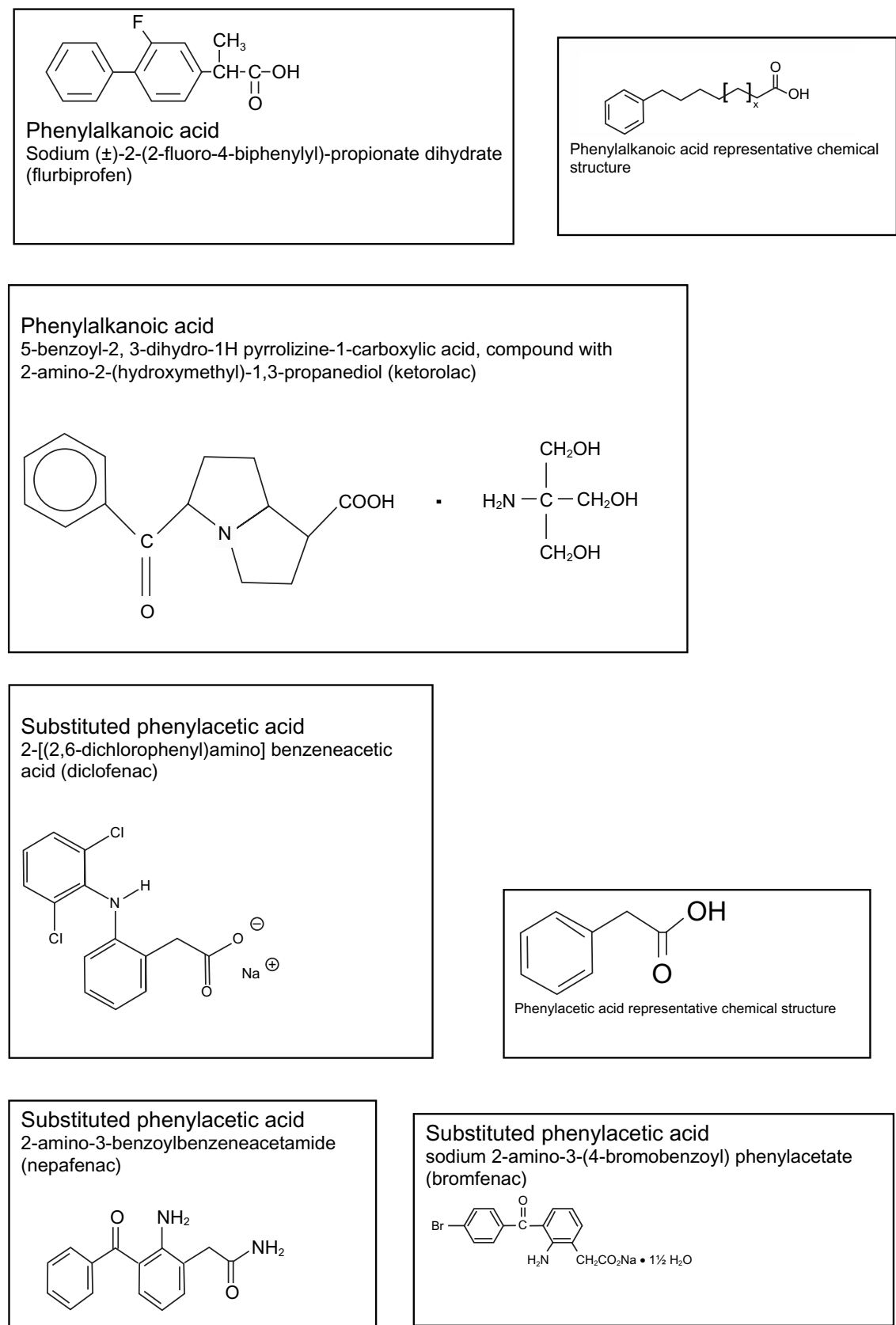

Figure 3 Chemical structures and names of topical ophthalmic NSAID products approved for use in the US. 
Nepafenac as an amide prodrug that requires hydrolysis to the more active amfenac entity, as noted in Figure 4.

Nepafenac as a parent compound exhibits weak intrinsic COX inhibitory activity (COX1 inhibitory activity IC50 $64.3 \mu \mathrm{M}$ ) (Hargrave et al 2002); however, it readily penetrates the rabbit cornea and distributes in all ocular tissues including aqueous humor, iris, ciliary body, retina, and choroid (Gamache et al 2000). Amfenac is an arylacetic acid derivative (2-amino-3-benzoylbenzene acetic acid), which exhibits potent antipyretic and analgesic properties. Amfenac is currently marketed in Japan as a systemic formulation for treatment of rheumatoid arthritis and for pain and/or inflammation after surgery $\left(\right.$ Fenazox $\left.^{\circledR}\right)$ (Needleman and Isakson 1997; Gamache et al 2000). A series of structural analogs of amfenac have been prepared to enhance the compound's therapeutic index (Walsh et al 1990; Ruiz et al 1993). Interestingly, oral use of nepafenac, the amide analog of 2-amino-3-benzoylbenzeneacetic acid, exhibited potent ant-inflammatory activity but greatly reduced intestinal toxicity (Walsh et al 1990).

Studies examining the in vitro comparative pharmacodynamic properties of nepafenac, amfenac, ketorolac, or bromfenac on COX activity demonstrated that ketorolac displays the greatest COX1 inhibitory activity while amfenac showed the greatest COX2 inhibitory potential (Walters et al 2007). Additional studies using PGE2 as a surrogate marker of COX activity have noted that ketorolac demonstrated greater effect in lowering aqueous levels of PGE2 levels compared to nepafenac (Bucci et al 2007). It should also be noted that nepafenac, as well as other topical ophthalmic NSAIDs, do not demonstrate activity on the 12(R) - HETE and 12(R) - HETrE inflammatory mediators generated within the cornea by the action of CYP450 enzymes on arachidonic acid.

Topical ophthalmic nepafenac targets the anterior segment of the eye, intraocular and vascularized tissues. Following topical application the onset of nepafenac activity is around
15 minutes and duration of action is greater than 8 hours (Stewart et al 2005) after topical administration $\left(\right.$ Nevanac $\left.^{\circledR}\right)$. Small quantifiable plasma concentrations of nepafenac and amfenac have been observed in subjects 2-3 hours after topical administration. After ocular administration the meansteady state $\mathrm{C}_{\max }$ of nepafenac and amfenac in serum were $0.310 \pm 0.014 \mathrm{ng} / \mathrm{mL}$ and $0.422 \pm 0.121 \mathrm{ng} / \mathrm{mL}$, respectively (Gamache et al 2000; Nevanac ${ }^{\circledR}$ ). After oral administration nepafenac in rats was eliminated in urine $(57 \%)$ and by the fecal route $(40 \%)$ over a 7 -day period (Bucci et al 2007). Nepafenac in the US was approved by the FDA (Food and Drug Administration) on August 19, 2005 as a priority drug approval (Lane 2006). Nepafenac is currently approved in the US only for treatment of pain and inflammation associated with cataract surgery $\left(\mathrm{Nevanac}^{\circledR}\right)$. It has been studied for the relief of pain and photophobia associated with photorefractive surgery and retinal edema secondary to diabetic retinopathy but is currently not approved for these indications in the US (Colin and Paquette 2006).

\section{Pharmacometrics of topically applied ophthalmic NSAIDs}

Drug formulation is an important factor affecting drug absorption and takes into consideration the $\mathrm{pH}$ of the drug, preservatives, and vehicle type. The corneal absorption of a drug depends on its lipid solubility and inversely on its polarity or degree of ionization. An important factor in the design of drugs for topical ophthalmic use that are commonly weak acids or bases involves the degree of penetration of a drug through the corneal epithelium. The more drug in its unionized form, the more likely it is to be lipid soluble and transferred by passive diffusion across the epithelial membrane. The $\mathrm{pH}$ of normal tears, which acts as a buffering system for many substances, varies between 6.5 and 7.6. Altering the $\mathrm{pH}$ solution of a slightly basic drug, for example from 6.2 to 7.5 ,

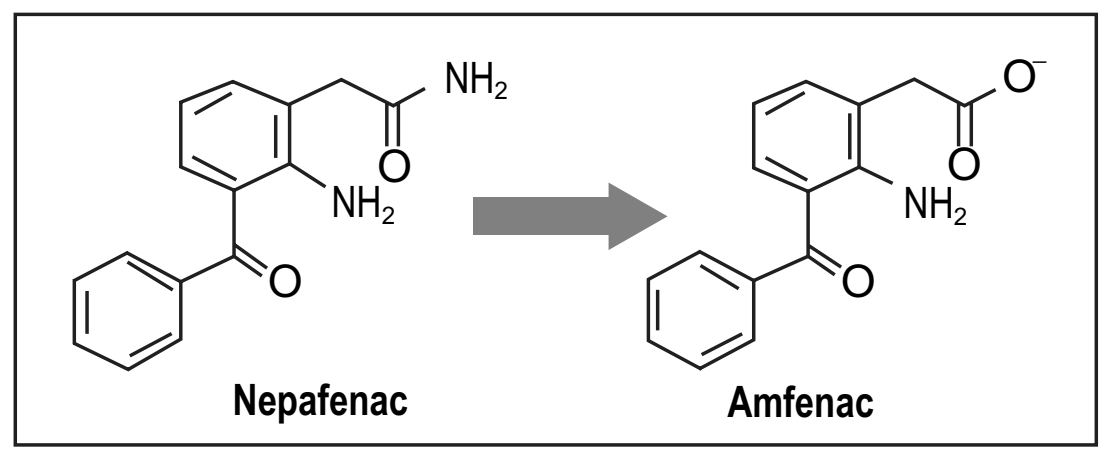

Figure 4 Deamination of nepafenac to the active compound amfenac. 
renders a drug to a more unionized state and therefore more lipid soluble, which therefore increases corneal penetration and, notably, systemic absorption as well. Hence ophthalmic nepafenac being a base and maintained as an ophthalmic solution at $\mathrm{pH} 7.4$ would exist more as a unionized drug and is therefore absorbed readily across the cornea at higher levels of tear $\mathrm{pH}$. The marked advantage of using prodrugs to enhance corneal absorption of ophthalmic drugs has been demonstrated using isolated rabbit corneal tissue (Ke et al 2000). In a rabbit model, corneal permeability of nepafenac was demonstrated by a permeability coefficient that was approximately 4,19 , and 28 times greater than diclofenac, bromfenac, and ketorolac respectively (Ke et al 2000; Linstrom and Kim 2006). However, it should be pointed out that significant differences exist between rabbit and human cornea both anatomically and in terms of pharmacokinetics of drug absorption (Owen et al 2007). In general, penetration of drugs applied to the rabbit cornea far exceeds that seen in the human due to the relative thinness of the rabbit cornea (Owen et al 2007).

It is also notable that bioactivation of nepafenac into the active amfenac entity is negligible in the cornea (Ke et al 2000). However, as noted previously nepafenac does appear to penetrate the rabbit cornea in amounts relatively higher than other NSAIDs, but once again a caveat must be noted concerning differences between the rabbit and human cornea. The tissue that appears to demonstrate the greatest hydrolytic activity for the nepafenac molecule has been shown in the rabbit to be the retina/choroid followed by the iris/ciliary body (Ke et al 2000). Bioactivation of nepafenac may also occur in aqueous humor presumably by aqueous hydrolytic enzymes. However, it is known that enzyme-protein concentration in the human aqueous is negligible with albumin being the largest contributor of aqueous protein concentration. Enzyme activity is also poorly discernable in the aqueous with exception of plasminogen and plasminogen activator (Blakemore 1995).

As an amide, nepafenac (benzoylbenzeneacetamide) may be considered chemically analogous to $N$-methylacetamide and may undergo similar water hydrolysis once reaching the aqueous humor (Zahn 2004). It is quite possible however that metabolism of nepafenac in the aqueous occurs by amide hydrolysis induced by water. At neutral $\mathrm{pH}$, nucleophilic attack by $\mathrm{OH}^{-}$is thought to be the rate limiting step of amide hydrolysis. The mechanism of water assisted hydrolysis has been investigated with use of $N$-methylacetamide using CarParrinello molecular dynamic (CPMD) simulation, which suggests a proton transfer and attack of the amide by the hydroxyl ion (Zahn 2004).
In vivo study in humans has shown that when applied topically to the cornea, nepafenac demonstrates both a faster time to $\mathrm{C}_{\max }$ as well as a higher aqueous humor concentration than either bromfenac or ketorolac (Walters et al 2007). The mean area under the time-concentration curve of aqueous drug concentration was found to be significantly higher for nepafenac than amfenac, ketorolac, or bromfenac (Walters et al 2007). However, it should be noted that the mean area under the curve for aqueous amfenac was found comparable to that of ketorolac (180.7 vs $176.9 \mathrm{ng} \times \mathrm{h} / \mathrm{mL}$, respectively) (Walters et al 2007). In contrast, additional studies have noted that levels of aqueous ketorolac following topical ophthalmic administration in humans far exceeds that of amfenac or nepafenac following 2 days of 4-times-a-day drug administration (Bucci et al 2007). This finding is curious in view of the marked penetration potential of the prodrug nepafenac entity.

It should be noted that benzalkonium chloride and other cationic surfactants increase ocular absorption of drugs by increasing corneal permeability by compromise of corneal integrity (Forrester et al 2002). Indeed alternative ophthalmic NSAIDs such as ketorolac, flurbiprofen, and bromfenac include benzalkonium chloride as a preservative, which may contribute to corneal permeability variances seen among these products.

\section{Efficacy of nepafenac in post-operative cataract surgery-related inflammation}

Cataract surgery is an invasive procedure that requires incision and cutting of ocular tissue as well as considerable intraocular tissue manipulation. Iatrogenic injury to the eye leads to disruption of the blood aqueous barrier with cellular infiltration leading to intraocular inflammation. Fibrin and protein accumulation in the anterior chamber may lead to complications of intraocular inflammation such as increased intraocular pressure as well as corneal endothelial precipitates. Adhesions of the iris to the angle and/or lens implant as well as opacification of posterior capsule may also be seen. Cellular debris on the lens implant and posterior capsule may also lead to poor visual recovery. In severe cases post-operative inflammation of the anterior segment secondary to surgical trauma may result in frank visual loss (Jampol et al 1994). Interestingly, topical NSAID treatment appears more effective than topical steroids in re-establishing the blood - aqueous barrier as quantitatively measured with anterior ocular flurophotometry (Jampol et al 1994). 


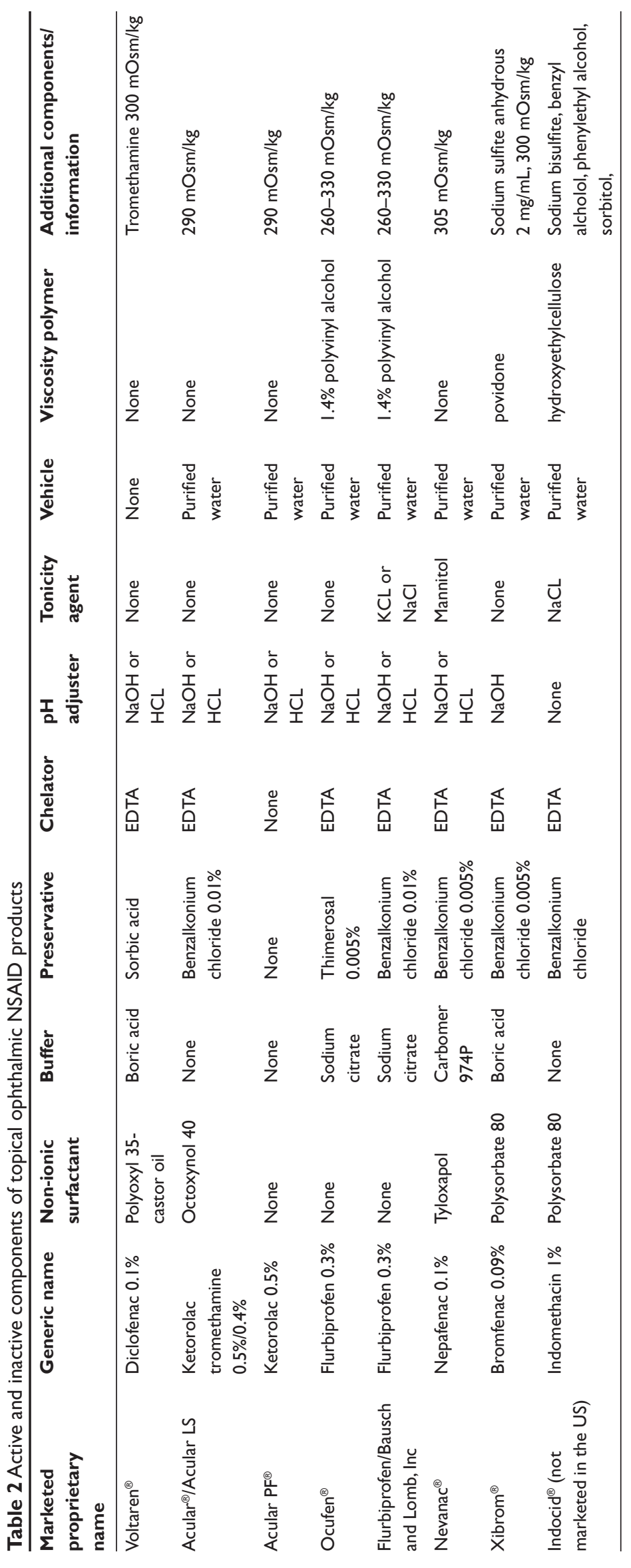


Additional uses of NSAIDS in regard to cataract surgery include prevention of surgically induced miosis that may hamper surgical outcome and treatment of complicating cystoid macular edema after lens removal. There is evidence that prophylactic use of NSAIDs prior to cataract surgery may in fact lessen post-operative inflammation avoiding intraocular pressure-related complications incurred with frequent administration of high dose corticosteroids postoperatively (Jampol et al 1994).

A total of 5 unpublished studies in humans have examined the use of nepafenac after cataract surgery (Nevanac ${ }^{\circledR}$; Lane 2006; National PBM drug monograph 2006). These studies included 1 pivotal trial (C-03-32), 1 efficacy and safety study (C-02-53), 2 dose response studies (C-95-93 and C-97-30), as well as 1 trial comparing safety and tolerability of nepafenac with diclofenac C-95-91. In studies C-02-53 and C-03-32 patients were randomized to receive nepafenac $0.1 \%$ at different dosing schedules, 1 drop daily, twice daily, 3 times a day, or placebo given with the above dosing regimen. All of the studies (except C-95-91) used aqueous cells and flare (signs of inflammation) as basis for evaluating the efficacy of the drug product. Using slit-lamp biomicroscopy is a standard practice in ophthalmology to evaluate inflammation, using aqueous cells and flare; the lower the score the lower the inflammation. The results of study C-02-53 demonstrated that 3-times-a-day regimen proved to be more efficacious than nepafenac given daily or twice daily, based upon the percentage of treatment failures (3 times a day $19.6 \%$ vs daily $25 \%$ vs twice daily $30 \%$ ).

As one would expect, nepafenac was superior to placebo in all three dose regimens. Both studies achieved statistical significance in terms of efficacy with more patients receiving nepafenac vs placebo pain free on days $1,3,7$, and 14 (National PBM drug monograph 2006). In a randomized double-blinded study of 476 patients evaluating safety and effectiveness of nepafenac in preventing and treating postcataract surgery inflammation and pain, a higher percentage of patients in the nepafenac group were pain-free at all visits $(83.1 \%-93 \%)$ compared with vehicle-treated patients $(41.6 \%-46.4 \%)(p<0.0001)$ (Lane et al 2007). While these studies firmly demonstrate the efficacy of nepafenac against a placebo, comparative drug - drug studies with other topical NSAIDs are less conclusive.

Notably, individual study of the effect of ketorolac on moderate to severe ocular inflammation after cataract surgery noted equivocal response in controlling pain $(\mathrm{p}=0.049)$ (Heier et al 1999). In contrast, studies with nepafenac showed a significant effect in reducing pain following cataract surgery
( $p<0.001)$ (Lane et al 2007). However, the study population examined by Lane differed significantly from the ketorolac population in that subjects did not demonstrate moderate to severe inflammation as noted in the ketorolac study, and were consecutively enrolled into the study simply because of the need for cataract surgery not because they demonstrated any particular level of discomfort. Additional reports have suggested that comparative studies between nepafenac and corticosteroids and other NSAIDs would be desirable (Colin and Paquette 2006). A study, however, by Nardi et al examined differences between ketorolac $0.5 \%$, nepafenac $0.1 \%$, and placebo for control of pain and inflammation following cataract extraction and posterior chamber lens implantation (Nardi et al 2007). Although findings by Nardi et al demonstrate a higher "cure rate" defined by a total absence of cell and flare on day 14 for the nepafenac product, by day 21 ketorolac slightly exceeded that of nepafenac in terms of cure rate. Moreover, despite manufacturer recommendations of 4 timesa-day day dosing for control of post-operative inflammation, ketorolac was dosed at a 3 times-a-day interval in the Nardi et al study which may have biased results toward nepafenac. It is noteworthy that subjects who received placebo demonstrated a dramatic improvement in anterior segment inflammation described by the presence of cell and flare from day 7 to 21 thus suggesting the confounding effect of normal healing on overall comparative product effectiveness.

\section{Safety of ophthalmic NSAIDs with a discussion of nepafenac}

Topical ophthalmic NSAIDs have become increasingly popular among cataract surgeons due to the fact that treatment can be initiated pre-operatively and continued post-operatively to provide not only better anti-inflammatory control with analgesia, but, as an added benefit, maintenance of intraoperative pupil dilation. Because of these favorable findings, the NSAID market has been growing through wider use not only in cataract surgery, but as an anti-inflammatory adjunct in procedures such as refractive and various types of retinal surgery as well. Although topical ophthalmic NSAIDs are in general considered safe and effective therapeutic entities when used in an appropriate manner, they are not without detriment and have been linked to various forms of corneal toxicity that in some cases have been particularly severe. As an example, diclofenac sodium ophthalmic solution (DSOS), previously manufactured by Falcon Pharmaceuticals, was associated with a cluster of corneal events defined by the presence of severe corneal melts that eventually led to removal of the Falcon product from the marketplace. Corneal melt associated with 
the other formulations of ophthalmic diclofenac have been reported as well $\left(\operatorname{Voltaren}^{\circledR}\right.$, Novartis Ophthalmics, East Hanover, NJ) (Gaynes and Fiscella 2002).

Adverse events characterized by severe corneal melts associated with the Falcon DSOS product were considered to be most likely related to the presence of the vitamin $\mathrm{E}$ based solubilizer tocophersolan found in the DSOS product (Gaynes and Fiscella 2002). Curiously, the occurrence of corneal infiltrates concomitantly with use of oral diclofenac has also been reported and is thought to be related to the increased production of lipoxygenase-derived LTB4, a polymorphonuclear chemotactic (Tabbara 2000). Of further interest, topical ophthalmic diclofenac has been found to decrease levels of substance P in human tears (Yamada et al 2002). Depletion of neuropeptides such as substance P within the corneal epithelium has been associated with delayed wound healing and may induce conditions conducive to the development of neurotrophic keratopathy (Yamada et al 2002). The association, however, of substance $\mathrm{P}$ depletion with other ophthalmic NSAIDs remains to be fully elucidated.

After removal of the Falcon DSOS from commercial use, the incidence of severe corneal events associated with NSAID use reported to the US FDA dropped precipitously. However, since removal of Falcon DSOS from the market in September 1999, scattered reports noting the association between severe corneal injury and use of topical NSAIDs have persisted, albeit not at the rate associated with the Falcon product. Ketorolac and bromfenac have both been associated with severe corneal injury; however, the circumstances of their use in these events is questionable (Asai et al 2006; Mian et al 2006). A report describing the occurrence of corneal melt with perforation occurring with topical bromfenac use also has been documented (Isawi and Dhaliwal 2007). Furthermore, a report has also been noted demonstrating the occurrence of a corneal melt associated with use of nepafenac (Wolf et al 2007). The latter circumstance involved a 56-year-old woman with graft-vs host disease who experienced a central corneal perforation after use of nepafenac after cataract surgery (Wolf et al 2007).

Commercially available nepafenac ophthalmic suspension is marketed in the US under the name Nevanac ${ }^{\circledR}$ and is combined with various inactive components to maintain $\mathrm{pH}$, tonicity, and sterility, including mannitol, sterile water, sodium chloride, edetate disodium, benzalkonium chloride, sodium hydroxide, and/or hydrochloric acid as well as carbomer 974P and tyloxapol. Carbomer 974 is a non-detergent water-based buffering agent that is a highly negatively charged high-molecular-weight polymer that provides thousands of active, ionizable carboxyl groups for acid buffering activity (AIDS Info). Clinical trials of Carbomer 974 as a buffering agent to maintain vaginal acidity in HIV studies demonstrated erythema and pruritis as the most common side effects associated with its use (AIDS Info). Tyloxapol is a detergent-based non-ionic liquid polymer of the alkyl aryl polyether alcohol type used as a surfactant to aid liquefaction (Tyloxapol). At concentrations of $0.2 \%-1.0 \%$ tyloxapol has been shown to induce concentration-dependent structural changes in high density lipoproteins (Yamamoto et al 1984). Tyloxapol also has been shown to inhibit lipoprotein lipase; however the long-term toxicologic effects of tyloxapol on the cornea at the concentration used in nepafenac ophthalmic solution is unknown (Bhatia and Wade 1991).

Corneal toxicity can be an issue with NSAID use and as such typically involves problems ranging from corneal stinging to punctuate keratopathy and persistent epithelial erosion. Nepafenac $0.1 \%$ ophthalmic suspension has the potential, as do all topical NSAIDs, to slow or delay healing and to cause keratitis (Gaynes and Fiscella 2002). Patients with complicated ocular conditions (eg, corneal denervation, corneal epithelial defects, diabetes mellitus, rheumatoid arthritis, and repeat and/or complex ocular surgeries) may be at an increased risk of corneal adverse events due to topical NSAID use (Gaynes and Fiscella 2002). Topical NSAIDS (including nepafenac) used concurrently with topical corticosteroids may increase the potential for slow or delayed healing. Therefore, the combined use of corticosteroids and topical NSAIDs may result in keratitis in susceptible patients, with prolonged use ( $>4$ weeks) resulting in epithelial breakdown, corneal thinning, corneal erosion, corneal ulceration or corneal perforation (Gaynes and Fiscella 2002; Nevanac ${ }^{\circledR}$ ). It should be pointed out, however, that NSAIDs-related corneal toxicity often occurs inconsistently with variable dose relationships, thereby suggesting etiologies perhaps more related to susceptibility rather than frank chemical toxicity as the defining cause of corneal injury (Flach 2001).

In addition to local toxicity, isolated reports of systemic toxicity have been associated with use of topical NSAIDs (Estes et al 1993; Chan 1995; Sharir 1997). Reports of asthma exacerbation, gastrointestinal erosions, and bleeding have been associated with use of systemic as well as topical ophthalmic NSAIDs (Estes et al 1993; Chan 1995; Sharir 1997). According to studies in rabbits, $74 \%$ of the administered topical ophthalmic dose of ketorolac reaches the systemic circulation through nasolacrimal drainage (Ling and Combs 1987). It is unclear, however, if similar findings are duplicated in humans. Nepafenac is not an inhibitor of the in 
vitro metabolism of the major cytochrome (CYP) isozymes (CYP1A2, CYP2C9, CYP2C19, CYP2D6, CYP2E1, and CYP3A4) at therapeutic concentrations used in ophthalmic indications $\left(\mathrm{Nevanac}^{\circledR}\right)$. Therefore, interactions involving concurrently used systemic drugs that are metabolized by CYP are unlikely. Drug interactions with nepafenac mediated by protein binding are also unlikely according to the opinion of the manufacturer $\left(\mathrm{Nevanac}^{\circledR}\right)$. Concurrent use of nepafenac with medications that prolong bleeding time may increase the risk of hemorrhage due to interference by nepafenac with thrombocyte aggregation. Moreover, there have been reports that ophthalmic non-steroidal anti-inflammatory drugs may increase bleeding in ocular tissues (including hyphema) in conjunction with ocular surgery (Gaynes and Fiscella 2002). One must be particularly cautious in initiating topical NSAID use particularly for long-term usage in the presence of concomitant risk factors such as with those who use concurrent systemic NSAIDs, use tobacco and/or alcohol, and/or are included in geriatric, pediatric, or other vulnerable populations.

Nepafenac warning labels indicate there is cross-sensitivity to acetylsalicylic acid, phenylacetic acid derivatives, and other non-steroidal anti-inflammatory agents $\left(\mathrm{Nevanac}^{\circledR}\right)$. Therefore caution should be used when treating individuals who have previously exhibited sensitivity to these drugs. As a rule the inhibition of $\mathrm{COX} 2$ determines the clinical efficacy of a topical NSAID. In systemic use NSAID selectivity for one COX isoform has been shown to affect clinical safety. Drugs with more selectivity for COX2 than COX1 tend to have fewer gastrointestinal side effects but have been associated with increased risk for hepatotoxicity, edema, hypertension, and cardiovascular problems. Although uncommon, the occurrence of systemic adverse events related to topical ophthalmic NSAIDS should not be discounted (Jampol et al 1994; Malhotra et al 2004; Warner et al 2004).

The most frequent adverse events reported in clinical trials with nepafenac to date have been ocular in nature; however, the definitive causality is obscure. Approximately $5 \%-10 \%$ of the patients demonstrated post-operative capsular opacity, decreased visual acuity, foreign body sensation, increased intraocular pressure, and a sticky sensation $\left(\operatorname{Nevanac}^{\circledR}\right)$. Fewer frequent ocular adverse events $(1 \%-5 \%)$ included conjunctival edema, corneal edema, dry eye, lid margin crusting, ocular discomfort, ocular hyperemia, ocular pain, ocular pruritis, photophobia, tearing, and vitreous detachment. Non-ocular adverse (1\%-4\%) events included hypertension, headache, nausea/vomiting, and sinusitis $\left(\mathrm{Nevanac}^{\circledR}\right)$. Concentrations of this drug have been evaluated at 15 times the commercial marketed dose without any significant complications in animal studies (McGee et al 2005; Walker et al 2005).

In the randomized vehicle-controlled clinical trial by Lane and colleagues evaluating nepafenac for treatment of pain and inflammation after cataract surgery, no ocular adverse events of definitive relationship to nepafenac therapy were reported (Lane et al 2007). Ocular adverse events reported by Lane et al occurring at an incidence of $1 \%$ or greater included decreased visual acuity, photophobia, capsule opacity, foreign body sensation, ocular hyperemia, ocular pruritis, ocular discomfort, dry eye, increased intraocular pressure, and blurred vision (Lane et al 2007). None of the events were considered serious and in large part of mild intensity and resolved without complication. These events occurred with similar incidence in both nepafenac $0.1 \%$ and the vehicle group. The incidence of ocular adverse events such as decreased visual acuity rates and capsular opacity were indeed similar in patients receiving nepafenac $0.1 \%$ and those receiving vehicle (3.2\% vs $3.8 \%$ and $2.0 \%$ vs $2.5 \%$ respectively (Lane et al 2007).

The use of NSAIDs after refractive surgery for control of pain and inflammation is a growing indication for this class of drug. In addition to typical LASIK procedures, refractive surgery also involves surface ablation photorefractive keratectomy such as laser-assisted sub-epithelial keratectomy (LASEK) and epi-LASEK. After surface ablation procedures, a contact lens is placed in the eye to promote epithelial regeneration. In one randomized double masked study of ketorolac $0.4 \%$ vs nepafenac $0.1 \%$ for control of pain after surface ablation, eyes treated with nepafenac tended to demonstrate greater corneal haze as well as slower epithelial healing compared with ketorolac, resulting in discontinuation of the study due to safety concerns (Trattler et al 2005). It appears that use of nepafenac after surface ablation greatly augments the risk of corneal toxicity, notably corneal haze and delayed healing, particularly if used for longer than a 3-day post-operative interval (Durrie et al 2006; Reilly and Cadwell 2006; William Trattler pers comm March 3, 2008). The rationale for nepafanac-related corneal injury following PRK is unclear as bioactivation of nepafenac within the cornea is reported to be very low (Colin and Paquette 2006). Persistent corneal haze after use of nepafenac after surface ablation procedures may, although unlikely, be related to direct chemical toxicity of the prodrug entity rather than a consequence of the pharmacodynamic actions of amfenac. More compelling is the notion of water-based hydrolysis of nepafenac within the matrix of the hydrophilic soft contact 
lens leading to nepafenac bioactivation. With repeated dosing, nepafenac may be adsorbed and accumulate within silicon hydrophilic bandage lenses which provide a substrate for water-based amide hydrolysis resulting in a steady source of amfenac leaching from the lens matrix.

It should be noted, however, that analysis of nepafenac in terms of corneal healing and analgesia following PRK as studied by Caldwell and Reily found that while analgesia was significantly enhanced in the nepafenac group, a concomitant delay in corneal wound healing was not evident. Corneal injury following PRK was indeed fully healed equally in both the nepafenac and placebo groups by post-operative day 5 (Caldwell and Reilly 2008). Further analysis by Donnefeld et al found that neither nepafenac nor ketorolac reduced corneal healing time following PRK and both drugs demonstrated a beneficial effect in terms of analgesia (Donnenfeld et al 2007). Colin and Paquette described corneal epithelial healing rate with use of $0.03 \%$ or $0.1 \%$ nepafenac or $0.1 \%$ diclofenac. Furthermore, Colin and Paquette found no difference in corneal epithelial healing rate among the three study formulations; however, a small corneal infiltrate was noted in the $0.03 \%$ nepafenac group that was deemed possibly related to the study medication (Colin and Paquette 2006). It should be noted, however, that in all studies mentioned describing PRK and corneal epithelial healing rate with various topical NSAIDs, subjects were followed for a maximum of 5-7 days with no comment on the appearance of the cornea following re-epithelization. Interestingly, corneal haze following PRK can occur weeks, months, or even years following PRK and is related to abnormalities in healing of the corneal stroma rather than epithelium (Majmudar et al 2000).

As a corollary to issues pertaining to refractive surgery, it is interesting to note that nepafenac is considered to demonstrate greater corneal analgesic effect compared with drugs such as diclofenac or ketorolac (Acosta et al 2007). This finding is largely due to the ability of nepafenac to partition into corneal epithelium quickly and efficiently compared more polar analogs. It has also been shown that unlike diclofenac, nepafenac does not exhibit local anesthetic qualities (Acosta et al 2007).

Reproduction studies performed with nepafenac in rabbits and rats at oral doses up to $10 \mathrm{mg} / \mathrm{kg} /$ day have revealed no evidence of teratogenicity due nepafenac, despite induction of maternal toxicity $\left(\mathrm{Nevanac}^{\circledR}\right)$. At this dose, the animal plasma exposure of nepafanac and amfenac was 80 and 680 times human plasma exposure for rabbits, respectively, when nepafanac was used at manufacturer recommended ophthalmic doses. In rats maternal toxic doses $\geq 10 \mathrm{mg} / \mathrm{kg}$ were associated with increased post-implantation loss, reduced fetal weights and growth, and reduced fetal survival. There have been no adequate, well-controlled trials for the use of nepafenac in pregnant women; therefore, its use should be avoided in the late stages of pregnancy (third trimester) due to the known effects of prostaglandin biosynthesis inhibition on the fetal cardiovascular system (closure of the ductus arteriosus). Nepafenac is considered pregnancy category C (Nevanac ${ }^{\circledR}$ ). Nepafenac has been shown to cross placental barrier in rats. Because animal reproduction studies are not always predictive of human response, nepafenac should be used during pregnancy only if the potential benefit justifies the potential risk to the fetus $\left(\mathrm{Nevanac}^{\circledR}\right)$.

Nepafenac should be used with caution in nursing mothers. Nepafenac was excreted in the milk of pregnant rats. Because it is not known whether this drug is excreted in human milk, caution should be exercised when nepafenac is administered to a nursing woman $\left(\mathrm{Nevanac}^{\circledR}\right)$.

Nepafenac has not been evaluated in long-term carcinogenicity studies. Increased chromosomal aberrations were observed in Chinese hamster ovary cells exposed in vitro to nepafenac suspension. Nepafenac did not impair fertility when administered orally to male and female rats at $3 \mathrm{mg} / \mathrm{kg}$ (approximately 90 and 380 times the plasma exposure to the parent drug, nepafenac, and active metabolite, amfenac, respectively, at the recommended human topical ophthalmic dose) $\left(\mathrm{Nevanac}^{\circledR}\right)$.

\section{Nepafenac dosage and administration for ocular use}

The approved FDA labeling for nepafenac states that 1 drop of nepafenac is to be applied to the affected eye(s) 3 times a day. Therapy begins 1 day prior to cataract surgery and continues the day of surgery and through the first 2 weeks of the post-operative period. The use of nepafenac beyond the recommended therapeutic time frame may increase the risk of adverse corneal events as noted in the FDAapproved drug labeling $\left(\mathrm{Nevanac}^{\circledR}\right)$. Safety of nepafenac has not been determined in pediatric patients below the age 10 years $\left(\mathrm{Nevanac}^{\circledR}\right)$. Each milliliter of nepafenac suspension contains $1 \mathrm{mg}$ of nepafenac and should be shaken well prior to instillation.

Topical ophthalmic NSAIDs such as ketorolac have been administered without incident in combination with other topical ophthalmic products including antibiotics, beta blockers, carbonic anhydrase inhibitors, cycloplegics, and mydriatics (Acular ${ }^{\circledR}$ 2003). Nepafenac would also be expected to 
be safely administered in combination with other topical ophthalmic products; however, dosage should be spaced at least in 5-minute intervals to prevent drug washout and dilution and to maximize drug absorption. The concomitant use of topical NSAIDs, however, in conjunction with topical and/or enteral corticosteroids must be carefully monitored, particularly among patients at high risk for corneal injury such as those with rheumatoid arthritis or fulminate collagen vascular disorders (Gaynes and Fiscella 2002).

\section{Conclusion}

Nepafenac is the first prodrug ophthalmic NSAID formulation approved for use in the US for the treatment of post-operative pain and inflammation after cataract surgery. Nepafenac itself has little activity on COX enzyme activity and requires deamination to the more active congener amfenac for therapeutic action. Although amfenac demonstrates marked COX inhibitory potential, differences in NSAID potency as described in comparative reviews of COX IC50 activity should not be the sole determinant of effective ophthalmic NSAID utilization clinically.

The theoretical advantage offered by nepafenac over other existing NSAIDs is in corneal penetration. However, the expected therapeutic advantage of nepafenac based on its corneal permeability profile and absorption is not fully recognizable in comparative assessment of clinical anti-inflammatory efficacy. The issue of bioactivation as it pertains to nepafenac is a key point in pharmacodynamics pertaining to the active amfenac entity. Although nepafenac is metabolized in the mammalian iris and retina, the rate of amide hydrolysis demonstrable in human aqueous has not been fully elucidated; therefore, comparative prediction regarding peak nepafenac concentration in aqueous as an implied indicator of effectiveness in the human is at best equivocal.

All commercially available topical ophthalmic NSAIDs are effective inhibitors of COX activity; whether or not one drug has greater or lower IC50 value is therefore not directly correlated with clinical indicators of therapeutic effectiveness. In the case of topical ophthalmic NSAIDs, practitioners should carefully weigh the cost-benefit of implementing "highly potent" new drug products because perturbations in pharmacodynamic response due to the inherent novelty in terms of chemical designs may outweigh the demonstrated replicative pharmacologic action of all topical ophthalmic NSAIDs.

\section{Disclosures}

Neither author has any conflicts of interest to disclose.

\section{References}

Acosta MC, Luna C, Graff G, et al. 2007. Comparative effects of the nonsteroidal anti-inflammatory drug nepafenac on corneal sensory nerve fibers responding to chemical irritation. Investig Ophthalmol Vis Sci, 48:182-8.

Acular $^{(\mathbb{B}}$ (ketorolac tromethamine) package labeling. 2003. Allergan Inc., Irvine, CA., USA.

AIDS Info. US Department of Health and Human Services. Carbomer 974. Accessed Jan 2008. URL: http://aidsinfo.nih.gov/DrugsNew/ DrugDetailNT.aspx?MenuItem=Drugs\&Search=On\&int_id=343.

Asai T, Nakagami T, Mochizuki M, et al. 2006. Three cases of corneal melting after instillation of a new non-steroidal anti-inflammatory drug. Cornea, 25:224-7.

Bhatia AJ, Wade GN. 1991. Effects of pregnancy and ovarian steroids on fatty acid synthesis and uptake in Syrian hamsters. Am J Physiol, 260: R153-R8.

Blakemore C, ed. 1995. Biochemistry of the Eye. Chapter 4. Aqueous, Iris, Ciliary Body and Trabeculum. In Perspectives in Vision Research. New York: Springer. p 155.

Bucci FA, Waterbury D, Amico, LM. 2007. Prostaglandin E $E_{2}$ inhibition and aqueous concentration of ketorolac $0.4 \%$ (Acular LS) and nepafenac $0.1 \%$ (Nevanac) in patients undergoing phacoemulsification. Am J Ophthalmol, 144:146-7.

Caldwell M, Reilly C. 2008. Effects of topical nepafenac on corneal epithelial healing time and postoperative pain after PRK: A bilateral, prospective, randomized masked trial. J Refract Surg, 24:377-82.

Chan TYK. 1995. Severe asthma attacks precipitated by NSAIDs. Ann Pharmacother, 29:199.

Colin J, Paquette B. 2006. Comparison of the analgesic efficacy and safety of nepafenac ophthalmic compared with diclofenac solution for pain and photophobia after excimer laser surgery. A phase II double masked trial. Clin Ther, 28:527-36.

Crofford LJ. 1997. COX-1 and COX-2 tissue expression: Implications and predictions. J Rheumatol, 24(Suppl 49):15-19.

Davis KL, Dunn MW, Schwartzman ML. 1990. Hormonal stimulation of 12(R)-HETE, a cytochrome P450 arachidonic acid metabolite. Curr Eye Res, 9:661-7.

Donnenfeld ED, Holland EJ, Durrie DS, et al. 2007. Double-masked study of the effects of nepafenac $0.1 \%$ and ketorolac $0.4 \%$ on corneal wound healing and pain after photorefractive keractomy. Adv Ther, 24:852-62.

Durrie D, Donnenfeld D, Holland E, et al. 2006. A double masked study of nepafenac $0.1 \%$ and ketorolac $0.4 \%$ for pain and epithelial healing following PRK. Presented at the joint meeting of the American Academy of Ophthalmology and Asia Pacific Academy of Ophthalmology. November 11-14, 2006, Las Vegas, Nevada.

Estes LL, Fuhs DW, Heaton AH, et al. 1993. Gastric ulcer perforation associated with use of injectable keterolac. Ann Pharmacother, 27:42-3.

Flach AJ. 1992. Cyclo-oxygenase inhibitors in ophthalmology. Surv Ophthalmol, 36:259-84.

Flach AJ. 2001. Corneal melts associated with topically applied nonsteroidal anti-inflammatory drugs. Trans Am Ophthalmol Soc, 99:205-12.

Forrester JV, Dick AD, McMenamin PG, et al. eds. 2002. The Eye. Basic Sciences in Practice. 2nd ed. Saunders.

Gamache DA, Graff G, Brady MT, et al. 2000. Nepafenac, a unique nonsteroidal prodrug with potential utility in the treatment of trauma-induced ocular inflammation: I. assessment of anti-inflammatory efficacy. Inflammation, 24:357-70.

Gaynes BI, Fiscella R. 2002. Topical nonnsteroidal anti- inflammatory drugs for ophthalmic use. Drug Safety, 25:2334-50.

Hargrave SL, Jung JC, Fini E, et al. 2002. Possible role of the vitamin E solubilizer in topical diclofenac on matrix metalloproeteinase expression in corneal melting. Ophthalmology, 109:343-350.

Heier J, Cheetham JK, Degryse R, et al. 1999. Keterolac tromethamine $0.5 \%$ ophthalmic solution in the treatment of moderate severe ocular inflammation after cataract surgery. A randomized vehicle controlled trial. Am J Ophthalmol, 127:253-9. 
Isawi H, Dhaliwal DK. 2007. Corneal melting and perforation in Stevens Johnson Syndrome following topical bromfenac use. J Cataract Refract Surg, 33:1644-6.

Jampol LM, Jain S, Weinreb RN. 1994. Non steroidal anti-inflammatory drugs and cataract surgery. Arch Ophthalmol, 112:891-4.

Ke TL, Graff G, Spellmann JM, et al. 2000. Nepafenac a unique nonsteroidal prodrug with utility in the treatment of trauma-induced ocular inflammation. II invitro bioactivation and permeation of external ocular barriers. Inflammation, 24:371-84.

Kulkarni, PS. 1991. The role of endogenous eicosanoids in rabbit -intraocular inflammation. $J$ Ocul Pharmacol Ther, 7:227-241.

Lane SS, MD, Modi SS, Lehmann RP, et al. 2007. Nepafenac ophthalmic suspension $0.1 \%$ for prevention of ocular inflammation associated with cataract surgery. J Cataract Refract Surg, 33:53-7.

Lane SS. 2006. Nepafenac: A unique nonsteroidal prodrug. Int Ophthalmol Clin, 46:13-20.

Lekhanont K, Park CY, Smith JA, et al. 2007. Effects of topical antiinflammatory agents in a botulinum toxin B-induced mouse model of kertatoconjunctivitis sicca. J Ocul Pharmacol Ther, 23:27-34.

Leonardi A, Busato F, Fregona I. 2000. Anti-inflammatory and anti-allergic effects of ketorolac tromethamine in the conjunctival provocation model. Br J Ophthalmol, 84:1228-32.

Ling TL, Combs DL. 1987. Ocular bioavailability and tissue distribution of ketorolac tromethamine in rabbits. J Pharm Sci, 76:289-94.

Linstrom R, Kim T. 2006. Ocular permeation and inhibition of ocular inflammation: an examination of data and expert opinion on clinical utility of nepafenac. Curr Med Res Opin, 22:397-404.

McGee DH, Heaton JD, Gruebbel RB, et al. 2005. Ocular effects of nepafenac ophthalmic suspension in new zealand white rabbits undergoing partial corneal incisions Investig Ophthalmol Vis Sci, 46:E-Abstract 2648.

Majmudar PA, Forstot L, Dennis RF, et al. 2000. Topical mitomycin-C for subepithelial fibrosis after refractive corneal surgery. Ophthalmology, 107:89-94.

Malhotra S, Shafiq N, Pandi P. 2004. COX 2 inhibitors: A class action or just vigorously promoted. MedGenMed, 6:6.

Masferrer JL, Rios AP, Schwartzman ML. 1990. Inhibition of renal, cardiac and corneal $\left(\mathrm{Na}^{+}-\mathrm{K}^{+}\right)$ATPase by 12(R)-hydroxyeicosatetraenoic acid. Biochem Pharmacol, 39:1971-4.

Meiyal PA, Dunn MW, Schwartzman ML. 2001. Detection of endogenous 12-hydroxyeicosatrienoic acid in human tears. Invest Ophthalmol Vis Sci, 42:328-32.

Mian, SI, Gupta A, Pineda R. 2006. Corneal ulceration and perforation with ketorolac tromethamine $\left(\right.$ Acular $^{\circledR}$ ) use after PRK. Cornea, 25:232-4.

Mieyal PA, Bonazzi A, Jiang H, et al. 2000. The effect of hypoxia on endogenous corneal epithelial eicosanoids. Invest Ophthalmol Vis Sci, 41:2170-6.

Morrow JD, Roberts LJ. 2001. Lipid-derived autocoids. In Hardman JG, Limbird LE ( eds). Goodman and Gilman's the Pharmacologic Basis of Therapeutics. 10th ed. New York, New York: McGraw-Hill. pp 679-80.

Nardi M, Lobo C, Bereczki A, et al. 2007. Analgesic anti-inflammatory effectiveness of nepafenac $0.1 \%$ for cataract surgery. Clinical Ophthalmology, 1:527-33.

National PBM drug monograph nepafenac $\left(\right.$ Nevanac $\left.^{\circledR}\right)$ ophthalmic suspension. 2006. VHA pharmacy benefits management strategic healthcare group and medical advisory panel. July.

Needleman P, Isakson P. 1997. The discovery and function of COX-2. J Rheumatol, 24(Suppl 49):9-14.

$\mathrm{Nevanac}^{\circledR}$ (nepafenac) package labeling. 2005-2006. Alcon Laboratory: Fort Worth, Texas, USA.

Nies AS. 2001. Principles of therapeutics. In Hardman JG, Limbird L (eds). Goodman and Gilman's the Pharmacologic Basis of Therapeutics. 10th ed. New York, New York. McGraw-Hill. p 50.

Owen GR, Brooks AC, James O, et al. 2007. A novel in vivo rabbit model that mimics human dosing to determine distribution of antibiotics in ocular tissue. J Ocul Pharmacol Ther, 23:335-42.
Periann A, Roch-Arveiller M, Girouind IP. 1985. In vivo effects of indomethacin and flurbiprofen on the locomotion of neutrophils elicited by immune and nonimmune inflammation in the rat. Eur J Pharmacol, 106:327-33.

Reilly CD, Cadwell MC. 2006. A double-masked study of nepafenac $0.1 \%$ and placebo on pain relief and epithelial healing following PRK Presented at the joint meeting of the American Academy of Ophthalmology and Asia Pacific Academy of Ophthalmology. November 11-14, 2006, Las Vegas, Nevada.

Ruiz J, Lopez M, Mila J, et al. 1993. QSAR and conformational analysis of the antiinflammatory agent amfenac and analogues. J Comput Aided Mol Des, 7:183-98.

Schwartzman ML, Abraham NG. 1990. Ocular cytochrome P-450 metabolism of arachidonate: Synthesis and bioassay. Methods Enzymol, 187:372-84

Schwartzman, ML, Bonazzi A, Mieyal P, et al. 2003. COX-2 lack of function in hypoxia-induced ocular surface inflammation. Thromb Res, 110:293-8.

Sellers RS, Sliverman I, Khan KMN. 2004. Cyclooxygenase 2 expression in the cornea of dogs with keratitis. Vet Pathol, 41:116-21.

Sharir M. 1997. Exacerbation of asthma by topical diclofenac. Arch Ophthalmol, 115:294-5.

Srinivasan BD, Kulkarni PS. 1989. Inhibitors of arachidonic acid cascade in the management of ocular inflammation. In Bito LZ, Stjernschantz $\mathrm{J}$ (eds). The Ocular Effect of Prostaglandins and Other Eicosanoids. New York: Alan R Liss. pp 229-49.

Stewart WC, Stewart R, Maxwell WA, et al. 2005. Preoperative and postoperative clinical evaluation of nepafenac $0.1 \%$ ophthalmic suspension for postcataract inflammation [abstract]. Presented at: American Society of Cataract and Refractive Surgery; April 18, 2005, Washington, DC.

Tabbara KF. 2000. Peripheral corneal infiltrates following oral diclofenac administration. Arch Ophthalmol, 118:1451.

Trattler W, McDonald M. 2007. Double masked comparison of ketorolac tromethamine $0.4 \%$ vs. nepafenac sodium $0.1 \%$ for postoperative healing rates and pain control in eyes undergoing surface ablation. Cornea, 26:665-6.

Tyloxapol, reagent grade. Accessed Jan 2008.URL: http://www.sigmaaldrich.com/catalog/search/ProductDetail/SIGMA/T8761.

Walker LM, Rice RL, Heaton JD, et al. 2005. Ocular effects of nepafenac ophthalmic suspension following three months of topical ocular administration to cynomolgus monkeys. Investig Ophthalmol Vis Sci, 46:E-Abstract 2649.

Walsh DA, Moran HW, Shamblee DA, et al. 1990. Antiinflammatory agents. 4. syntheses and biologic evaluation of potential prodrugs of 2 amino-3- benzoylbenzenacetic acid and 2-amino-3- (4-chlorobenzoyl) benzeneacetic acid. J Med Chem, 33:2296-304.

Walters T, Raizman M, Ernest P, et al. 2007. In vivo pharmacokinetics and in vitro pharmacodynamics of nepafenac, amfenac, ketorolac and bromfenac. J Cataract Refract Surg, 33:1539-45.

Warner TD. 2001. Determinations of COX-1/COX-2 selectivity. relationships to clinical effects. The Toxicology Forum, Winter Meeting.

Warner TD, Mitchell JA. 2004. Cyclooxygenase: New forms, new inhibitors, and lessons from the clinic. FASEB J. 18:790-804.

Wolf EJ, Kleiman LZ, Schrier A. 2007. Nepafenac-associated corneal melt. $J$ Cataract Refract Surg, 33:1974-5.

Xiaojun L, Weilin X, Reed D, et al. 1995. Nonsteroidal anti-inflammatory drugs cause apoptosis and induce cyclooxygenases in chicken embryo fibroblasts. Proc Natl Acad Sci USA, 92:7961-5.

Yamada M, Ogata M, Kawai M, et al. 2002. Topical diclofenac sodium decreases substance P content in tears. Arch Ophthal, 120:51-4.

Yamamoto K, Byrne R, Edelstein C, et al. 1984. In vitro effect of triton WR-1339 on canine plasma high density lipoproteins. J Lipid Res, 25:770-9.

Zahn, D. 2004. On the role of water amide hydrolysis. European Journal of Organic Chemistry, 4020-3. 